\title{
Estimasi Nilai Years of Life Lost (YLL) Penyakit Kanker Akibat Secondhand Smoke di Indonesia
}

\author{
Estimated of Years of Life Lost (YLL) Cancer Disease Due to Secondhand \\ Smoke in Indonesia
}

\author{
Kadek Ida Krisnadewi*, Susi Ari Kristina, Chairun Wiedyaningsih \\ Fakultas Farmasi, Universitas Gadjah Mada \\ Corresponding author: Kadek Ida Krisnadewi: Email: kadekidakrisnadewi@gmail.com \\ Submitted: 15-09-2019 Revised: 20-09-2019 Accepted: 20-09-2019
}

\begin{abstract}
ABSTRAK
Paparan rokok pada perokok pasif meningkatkan risiko terjadinya penyakit jantung koroner dan stroke pada orang dewasa, dan juga gangguan pernafasan hingga kematian pada anak-anak. Perokok pasif menjadi penyebab 42.000 kematian pada kanker, dan sebanyak 7000 lebih kematian disebabkan oleh kanker paru. Tujuan penelitian ini adalah menghitung beban ekonomi dari sisi Years of Life Lost (YLL). Estimasi nilai years of life lost (YLL) untuk 6 penyakit kanker akibat perokok pasif diambil per kelompok jenis kelamin. YLL dihitung dengan mengalikan angka harapan hidup menurut standar WHO Life table dan estimasi kematian akibat kanker.Diperoleh hasil nilai YLL laki-laki dan perempuan apabila dijumlahkan yakni, nilai terbesar ialah pada kanker paru-paru (19.823 person years), diikuti dengan kanker kolon (19.007 person years), kanker pankreas (14.155 person years), kanker perut (3.372 person years), kanker kandung kemih (3.251 person years) dan kanker laring (1.242 person years). Kesimpulannya, terdapat 3 penyakit kanker akibat perokok pasif yang menimbulkan jumlah kehilangan tahun (akibat kematian dini YLL) terbesar ialah kanker paru-paru, kanker kolon dan kanker pankreas. Pertimbangan indikator YLL penting dilakukan sebagai sumber informasi dalam penentu kebijakan. Nilai YLL dari kanker paru cukup tinggi, hal ini perlu menjadi perhatian serius bagi pemerintah dan tenaga kesehatan agar lebih mewaspadai dan menghimbau terkait bahayanya paparan perokok pasif bagi masyarakat.
\end{abstract}

Kata kunci: Years of life lost; Kanker; Perokok pasif

\begin{abstract}
Exposure to secondhand smoke increases the risk of coronary heart disease and stroke in adults, and also respiratory problems in children. Passive smoking is the cause of 42,000 deaths, and as many as 7,000 more deaths are caused by lung cancer. The purpose of this study is to calculate the economic burden from the Years of Life Lost (YLL). Estimated Years of life lost (YLL) values for 6 cancers due to passive smoking are taken per gender group. YLL is calculated by multiplying life expectancy according to the WHO Life table standard and estimation of cancer deaths. YLL results obtained, if the YLL values of men and women are added up, the largest value is in lung cancer $(19,823$ person years), followed by colon cancer $(19,007$ person years $)$, pancreatic cancer $(14,155$ person years), stomach cancer (3,372 person years), bladder cancer $(3,251$ person years) and laryngeal cancer $(1,242$ person years $)$. In conclusion, there are 3 cancers caused by passive smoking that cause the number of years lost due to premature death are lung cancer, colon cancer and pancreatic cancer. The consideration of YLL indicators is important as a source of information in policy makers. The YLL value of lung cancer is quite high, this might need serious attention for the government and health workers to be more aware and appealing to the danger of exposure to passive smoking for the community.
\end{abstract}

Keywords: Years of life lost; Cancer; Passive smoking

\section{PENDAHULUAN}

Prevalensi perokok di Indonesia masih sangat tinggi. Indonesia menjadi urutan kedua di dunia sebagai konsumsi rokok terbesar setelah China dan menjadi yang pertama di Asia
Tenggara (Lian dkk., 2018). Tingginya angka perokok di Indonesia menyebabkan risiko orang yang terpapar atau menghirup asap rokok sebagai perokok pasif juga meningkat. 
Perokok pasif ialah seseorang yang terpaparan asap rokok baik dari asap yang yang timbul dari bakaran rokok maupun asap yang timbul dari hembusan perokok. Asap yang membakar ujung rokok lebih berbahaya dibandingkan asap yang dihirup oleh perokok, hal ini dikarenakan asap yang mengepul dari ujung rokok tersebut tidak terfilter (Cleveland, 2017). Karbonmonoksida dalam asap rokok yang mengepul lebih banyak lima kali lipat dibandingkan dengan asap utama yang dihisap. Karbonmonoksida dapat bertahan selama beberapa jam di dalam ruangan setelah perokok berhenti merokok (Janah dan Martini, 2017). Kondisi ini perlu menjadi perhatian yang cukup serius kerena terdapat beberapa penelitian yang melaporkan bahwa paparan perokok pasif dapat menyebabkan sejumlah masalah kesehatan salah satunya ialah kanker.

Perokok pasif menjadi penyebab 42.000 kematian, dan sebanyak 7000 lebih kematian disebabkan oleh kanker paru (American Cancer Society, 2016). Paparan rokok pada perokok pasif juga meningkatkan risiko terjadinya penyakit jantung koroner dan stroke pada orang dewasa, dan juga gangguan pernafasan hingga kematian pada anak-anak. (Chen dkk., 2015)

Menurut penelitian, paparan terhadap perokok pasif akan meningkatkan risiko terkenanya penyakit kanker, terutama kanker paru dan kanker payudara khususnya pada wanita (Kim dkk., 2018). Jumlah angka kejadian penyakit kanker yang ditunjukan Global Cancer Statistics (GLOBOCAN), sekitar 14,1 juta kasus angka kejadian dan 8,2 juta kasus angka kematian yang terjadi pada tahun 2012 di seluruh dunia.

Kanker menyebabkan beban ekonomi yang besar bagi individu, keluarga maupun masyarakat. Kanker tidak hanya menyebabkan kecacatan dan kematian, namun juga biaya pengobatan yang sangat besar dan hilangnya produktivitas kerja mengakibatkan defisit finansial. Akibatnya, beban yang ditimbulkan akibat kanker memiliki implikasi menghambat upaya penurunan kemiskinan dan pembangunan ekonomi. Perserikatan Bangsa Bangsa (PBB) telah mengidentifikasi implikasi sosial ekonomi penyakit penyakit kronik, termasuk kanker, sebagai indikator utama dalam Millennium Development Goals (World Health Organization, 2017). Salah satu parameter yang bisa menjadi indikator implikasi beban ekonomi dari suatu penyakit kronik ialah Years of Life Lost (YLL).

Years of Life Lost (YLL) merupakan cara mengukur perkiraan kematian dini dengan menghitung jumlah tahun produktif suatu populasi yang hilang akibat kematian dini yang disebabkan oleh penyakit tertentu. Tujuan penelitian ini adalah menghitung beban ekonomi dari sisi Years of Life Lost (YLL).

\section{METODOLOGI}

Penelitian ini merupakan penelitian epidemiologi deskriptif dengan menggunakan estimasi berdasarkan data prevalensi dengan rincian per penyakit. Penelitian ini mengkaji proporsi kejadian dari penyakit kanker akibat perokok pasif yang nantinya dinyatakan dalam Secondhand smoke Attributable Fractions (SAFs) dan beban penyakit kanker akibat perokok pasif. Dari nilai SAF tersebut kemudian dicari nilai dari Years of Life Lost (YLL).

\section{Prevalensi Perokok Pasif di Indonesia}

Prevalensi perokok pasif di Indonesia berdasarkan jenis kelamin diperoleh dari Global Adult Tobacco Survei (GATS): Indonesia Report 2011 (Kementrian Kesehatan dkk., 2012).

\section{Penentuan Jenis Kanker}

Jenis kanker yang diteliti berdasarkan pada studi epidemiologi dan publikasi ilmiah dari sumber IARC yang membahas terkait dampak perokok pasif terhadap kanker. Jenis kanker yang dipilih ialah kanker dengan nilai RR lebih dari 1. Prevalensi angka kematian kanker pada penelitian ini diperoleh dari data BPJS 2018. Pada penelitian ini terdapat 6 jenis kanker yang diteliti.

\section{Estimasi Secondhand smoke Atributable Fractions (SAFS) \\ Secondhand smoking- attributable} fraction adalah proporsi kesakitan dan kematian yang diakibatkan oleh perokok pasif. Rumus SAFs terdiri dari 2 komponen utama yakni, prevalensi perokok pasif di populasi nasional yang didapat dari GATS 2012 dan relative risk (RR) didapat dari International Agency for Research on Cancer (IARC) (International Agency for Research on Cancer, 2004). Adapun rumus SAFs adalah

$$
\text { SAFs }=\frac{p(R R i-1)}{1+p(R R i-1)}
$$

(Zahra et al., 2016) 
Tabel I. Relative risk dan SAF kanker akibat perokok

\begin{tabular}{lcccc}
\hline \multirow{2}{*}{ Kanker } & \multicolumn{2}{c}{ RR } & L & \%SAFs \\
\cline { 2 - 5 } & $\mathbf{L}$ & $\mathbf{P}$ & 50,90 & 18,86 \\
Paru & 2,28 & 1,31 & 42,16 & 37,50 \\
Kolon & 1,9 & 1,8 & 79,54 & 78,26 \\
Perut & 5,8 & 5,89 & 37,79 & 63,30 \\
Kandung Kemih & 1,75 & 3,3 & 80,19 & 78,95 \\
Pankreas & 6 & 6 & 60,61 & 58,76 \\
Laring & 2,9 & 2,9 & & \\
\hline
\end{tabular}

Keterangan: L (Laki-laki); P (Perempuan)

Tabel II. Jumlah estimasi kematian kanker akibat perokok pasif

\begin{tabular}{lcccc}
\hline \multirow{2}{*}{ Kanker } & \multicolumn{2}{c}{ Jumlah angka kematian kanker } & \multicolumn{2}{c}{$\begin{array}{c}\text { Jumlah angka kematian kanker } \\
\text { akibat perokok pasif }\end{array}$} \\
\cline { 2 - 5 } & L & P & L & P \\
\hline Paru & 1.727 & 808 & 879 & 152 \\
Kolon & 1.120 & 924 & 472 & 347 \\
Perut & 121 & 68 & 96 & 53 \\
Kandung Kemih & 286 & 97 & 108 & 61 \\
Pankreas & 265 & 249 & 213 & 196 \\
Laring & 97 & 14 & 59 & 8 \\
Total & 3.616 & 2.160 & 1,827 & 817 \\
\hline
\end{tabular}

Keterangan: L (Laki-laki); P (Perempuan)

nilai p adalah prevalensi perokok pasif, nilai RR ialah relative risk, dan $i$ adalah sub-scrip kategori penyakit tertentu.

Years of life years (YLL)

Tahapan dalam mengestimasi nilai YLL yang pertama ialah mengumpulkan jumlah angka kematian kanker yang diperoleh dari data BPJS 2018. Data ini kemudian dikalikan dengan nilai SAF untuk memperoleh data jumlah kematian kanker akibat perokok pasif. Kedua, diperlukan data angka harapan hidup yang diperoleh dari WHO Life table 2016. Kemudian YLL dapat diperoleh dari rumus sebagai berikut:

$$
\text { YLL = N X L }
$$

nilai $\mathrm{N}$ adalah jumlah kematian kanker akibat perokok pasif dan nilai $\mathrm{L}$ ialah angka harapan hidup dari WHO Life Table 2016.

\section{HASIL DAN PEMBAHASAN}

Years of life lost (YLL) adalah indikator untuk memperkirakan angka tahun yang hilang karena kematian dini dari penyakit kanker akibat perokok pasif. Secara berurutan semakin muda usia seseorang mengalami kematian dini maka semakin tinggi nilai YLL (Donev et al., 2010). Nilai YLL didapatkan dari perhitungan angka kematian akibat dari perokok pasif dijumlahkan dengan standar angka harapan hidup di Indonesia dimana dalam penelitian ini menggunakan data dari WHO Life table tahun 2016.

Berdasarkan data Tabel I hasil perhitungan SAF, dapat dilihat bahwa proporsi kejadian penyakit kanker akibat perokok pasif di Indonesia paling tinggi yaitu pada laki-laki dengan kanker pankreas $(80,19)$, diikuti oleh kanker perut pada laki-laki $(79,54)$, kanker pankreas pada perempuan $(78,95)$, dan kanker perut pada perempuan $(78,26)$.

Angka kematian penyakit kanker akibat perokok pasif diperoleh dari mengalikan nilai SAF dengan angka kematian penyakit kanker dari BPJS 2018. Dari perhitungan tersebut diperoleh jumlah kematian kanker akibat rokok paling tinggi ialah pada kanker paru laki-laki (879 kasus) diikuti oleh kanker kolon pada lakilaki (472 kasus), kanker pankreas pada laki-laki (213 kasus) dan kanker pankreas pada 
Tabel III. YLL penyakit kanker akibat perokok pasif di Indonesia

\begin{tabular}{lccc}
\hline \multirow{2}{*}{ Kanker } & \multicolumn{2}{c}{ Years of life lost (YLL) (person years) } \\
\cline { 2 - 4 } & $\mathbf{L}$ & $\mathbf{P}$ & Total \\
\hline Paru & 16.295 & 3.528 & 19.823 \\
Kolon & 10.004 & 9.003 & 19.007 \\
Perut & 1.953 & 1.419 & 3.372 \\
Kandung Kemih & 1.916 & 1.335 & 3.251 \\
Pankreas & 4.161 & 9.994 & 14.155 \\
Laring & 1.023 & 219 & 1.242 \\
Total & 172.415 & 274.368 & 35.352 \\
\hline
\end{tabular}

Keterangan: L (Laki-laki); P (Perempuan)

perempuan (196 kasus). Dari data tersebut dapat dilihat bahwa angka kematian tertinggi kanker akibat perokok pasif ialah pada kanker paru, kanker kolon dan kanker pankreas. Secara keseluruhan, sebanyak 2,644 (45,77\%) kematian kanker disebabkan oleh perokok pasif. Pada Tabel III menunjukkan nilai YLL terbesar laki-laki ialah pada kanker paru-paru (16.296 person years), diikuti dengan kanker kolon (10.004 person years), kanker pankreas (4.161 person years), kanker perut (1.953 person years), kanker kandung kemih (1.916 person years) dan kanker laring (1.023 person years). Sehingga, YLL terbesar adalah pada laki-laki dengan kanker paru-paru, kanker kolon dan kanker pankreas.

Nilai YLL terbesar perempuan ialah pada kanker pankreas (9.994 person years), diikuti dengan kanker kolon (9.003 person years), kanker paru-paru (3.528 person years), kanker perut (1.419 person years), kanker kandung kemih (1.335 person years) dan kanker laring (219 person years). Sehingga, jumlah kehilangan tahun yang hilang akibat kematian dini terbesar pada perempuan yakni kanker pankreas, kanker kolon dan kanker paru-paru. Apabila jumlah YLL laki-laki dan perempuan dijumlahkan nilai terbesar ialah pada kanker paru-paru (19.823 person years), diikuti dengan kanker kolon (19.007 person years), kanker pankreas (14.155 person years), kanker perut (3.372 person years), kanker kandung kemih (3.251 person years) dan kanker laring (1.242 person years).

Parameter YLL dapat mewakili beban populasi dari kanker. Parameter ini memiliki nilai tambah karena menghitung nilai kematian suatu populasi akibat efek dari suatu paparan dalam hal ini perokok pasif. Enam penyakit kanker akibat perokok pasif yang diteliti, kanker paru merupakan kanker dengan total nilai YLL tertinggi yakni (19.823 person years), diikuti dengan kanker kolon (19.007 person years) dan kanker pankreas (14.155 person years). Pertimbangan indikator YLL penting dilakukan sebagai sumber informasi dalam penentu kebijakan. Nilai YLL kanker paru cukup tinggi hal ini mungkin perlu menjadi perhatian serius bagi pemerintah dan tenaga kesehatan agar lebih mewaspadai dan menghimbau terkait bahayanya paparan perokok pasif bagi masyarakat. Data penelitian ini hanya mencakup 6 jenis kanker saja, dikarenakan masih terbatasnya literatur terkait nilai RR pada kanker akibat perokok pasif.

\section{KESIMPULAN}

Nilai total YLL keseluruhan dar 6 penyakit kanker (kanker paru, kolon, kandung kemih, laring, perut dan pankreas) akibat perokok pasif ialah 35.352 person years. Dengan rincian nilai YLL tertinggi disebabkan oleh kanker paru-paru (19.823 person years), diikuti dengan kanker kolon (19.007 person years), kanker pankreas (14.155 person years), kanker perut (3.372 person years), kanker kandung kemih (3.251 person years) dan kanker laring (1.242 person years). Adapun 3 penyakit kanker akibat perokok pasif yang menimbulkan jumlah kehilangan tahun akibat kematian dini terbesar ialah kanker paru-paru, kanker kolon dan kanker pankreas. Pertimbangan indikator YLL penting dilakukan sebagai sumber informasi dalam penentu kebijakan.

\section{UCAPAN TERIMA KASIH}

Penulis mengucapkan terima kasih kepada Badan Penyelenggara Jaminan Sosial (BPJS) karena sudah bersedia memberikan data untuk diteliti. 


\section{DAFTAR PUSTAKA}

American Cancer Society, 2016. Secondhand Smoke, Just the Fact, American, American Cancer Society

Burnet, N.G, Jefferies, S.J., Benson, R.J., 2005 Years Of Life Lost (YLL) From Cancer Is An Important Measure of Population Burden - And Should Be Considered When Allocating Research Funds, BMJ Open, 92

Chen, J., Wang, M.-P., Wang, X., Viswanath, K., Lam, T.-H., dan Chan, S.S., 2015b. Secondhand smoke exposure (SHS) and health-related quality of life (HRQoL) in Chinese never smokers in Hong Kong. BMJ Open, 5: e007694.

Cleveland, 2017. 'Dangers of Secondhand Smoke', Cleveland Clinic. URL: https://my.clevelandclinic.org/health/ar ticles/10644-secondhand-smokedangers (diakses tanggal 9/7/2019).

Donev D, Zaletel,K.L., Bjegovic V, dan Burazeri,G., 2013. Measuring burden of disease: Disability-Adjusted Life Years (DALY). Jacobs Verlag.

International Agency for Research on Cancer (Editor), 2004. IARC Monographs on the Evaluation of Carcinogenic Risks to Humans, Volume 83, Tobacco Smoke and Involuntary Smoking: This Publication Represents the Views and Expert Opinions of an IARC Working Group on the Evaluation of Carcinogenic Risks to Humans, Which Met in Lyon, 11 - 18 June 2002. IARC, Lyon.

Janah, M. dan Martini, S., 2017. Hubungan Antara Paparan Asap Rokok Dengan Kejadian Prehipertensi Relationship
Between Secondhand Smoke And Prehypertension. Jurnal Manajemen Kesehatan Yayasan RS.Dr. Soetomo, 3: 131

Lian, T.Y., Dorotheo, U., Ritthiphakdee, B., Kolandai, D.M.A., Villarreiz, D.D., Ratanachena, S., dkk., 2018. The Tobacco Control Atlas: ASEAN Region, Fourth Edition 144.

Kementrian Kesehatan, R. of I., CDC Foundation, World Health Organization, dan Regional Office for South-East Asia, 2012. Global Adult Tobacco Survey: Indonesia Report 2011. World Health Organization, Regional Office for SOuth Easr Asia, New Delhi.

Kim, A.S., Ko, H.J., Kwon, J.H., dan Lee, J.M., 2018. Exposure to Secondhand Smoke and Risk of Cancer in Never Smokers: A MetaAnalysis of Epidemiologic Studies. International Journal of Environmental Research and Public Health, 15: 1981.

Murray, C.J.L. (Editor), 1996. The Global Burden of Disease: A Comprehensive Assessment of Mortality and Disability from Diseases, Injuries, and Risk Factors in 1990 and Projected to 2020; Summary, Global burden of disease and injury series. Harvard School of Public Health [u.a.], Cambridge.

World Health Organization, 2017. Tobacco Control for Sustainable Development. World Health Organization, Regional Office for South East Asia, New Delhi.

Zahra, A., Cheong, H.-K., Lee, E.-W., dan Park, J.H., 2016. Burden of Disease Attributable to Secondhand Smoking in Korea. Asia Pacific Journal of Public Health, 28: 737750. 